\title{
Understanding why adult participants at the World Senior Games choose a healthy diet
}

\author{
Ray M Merrill*1 and Eric C Shields ${ }^{2}$
}

\author{
Address: ${ }^{1}$ Department of Health Science, College of Health and Human Performance, Brigham Young University, Provo, Utah, USA and \\ 2Department of Nutrition, Dietetics, and Food Science, College of Biology and Agriculture, Brigham Young University, Provo, Utah, USA \\ Email: Ray M Merrill* - Ray_Merrill@byu.edu; Eric C Shields - ecs26@email.byu.edu \\ * Corresponding author
}

Published: 22 November 2003

Nutrition Journal 2003, 2:16

This article is available from: http://www.nutritionj.com/content/2/I/16

(C) 2003 Merrill and Shields; licensee BioMed Central Ltd. This is an Open Access article: verbatim copying and redistribution of this article are permitted in all media for any purpose, provided this notice is preserved along with the article's original URL.
Received: 0 I September 2003

Accepted: 22 November 2003

\begin{abstract}
Background: Identifying those seniors most likely to adopt a healthy diet, the relative importance they place on certain perceived benefits associated with a healthy diet, and whether these perceived benefits are associated with selected demographic, lifestyle, and health history variables is important for directing effective dietary health promotion programs.

Methods: Analyses are based on a cross-sectional convenience sample of 670 seniors aged 50 years and older at the 2002 World Senior Games in St. George, Utah. Data are assessed using frequencies, bivariate analysis, analysis of variance, and multiple logistic regression analysis.

Results: Fruit and vegetable consumption was significantly higher in individuals aged $70-79$, in women, in those not overweight or obese, and in those with excellent overall health. Dietary fiber consumption was significantly higher in former or never smokers, current and previous alcohol drinkers, in those not overweight or obese, and in those with excellent health. The strongest motivating factors identified for adopting a healthy diet were to improve the quality of life, to increase longevity, and to prevent disease. Of intermediate importance were the need to feel a sense of control and to satisfy likes or dislikes. Least important were the desire to experience a higher level of spirituality, social reasons, and peer acceptance.

Conclusion: Seniors who have adopted a healthy diet are more likely to have chosen that behavior because of perceived health benefits than for personal and social benefits. Overweight or obese individuals and those in poor health were less likely to be engaged in healthy eating behavior and require special attention by dieticians and public health professionals.
\end{abstract}

\section{Background}

Six of the ten leading causes of death in the United States (coronary heart disease, stroke, cancer, diabetes, atherosclerosis, and liver disease) are associated with poor food choices and overeating [1]. The U.S. Department of Agriculture Dietary Guidelines for Americans recommends consuming a varied diet that is low in fat, saturated fat, and cholesterol, as well as moderate in sodium, sugar, and alcohol for those who drink [2]. Although the benefits of making proper food choices are clear, the determinants of sustained healthy eating often remain unclear. Food choices are influenced by a complex combination of factors, including social influences, food availability and cost, nutritional value and dietary knowledge and awareness, and sensory considerations. The relative importance 
of these factors in promoting proper food choices also remains unclear.

Research has shown that perceived impressions of the social acceptability of particular foods, combined with social pressure to change dietary intake, influence food choices [3]; socioeconomic status is associated with dietary choices, with less educated, lower income individuals purchasing fewer types of fruit and vegetables and being less likely to buy foods that are low in fat, sodium, and sugar than those of higher status [4]; the availability, cost, and familiarity of food are predictors of food intake $[5,6]$; individual beliefs about food and desire to consume a healthy diet to prevent disease and improve health are determinants of dietary intake [3]; and taste and food preferences are determinants of food choice $[7,8]$.

This paper will assess dietary behavior among a group of seniors according to selected demographic, lifestyle, and disease history variables. Among those identified as conscientious about their diet, the level of importance placed on selected potential benefits associated with a proper diet, as well as the extent the perceived benefits are related to selected variables will be explored. Identifying the characteristics of seniors most likely to adopt a proper diet, the relative importance placed on certain perceived benefits for a healthy diet, and whether these perceived benefits are associated with other variables will provide useful information for developing health programs directed at improving diet among seniors.

\section{Methods \\ Data}

Every October the World Senior Games, held in St. George, Utah, attract seniors from throughout the world. In addition to participating in a wide range of athletic events, seniors are encouraged to attend presentations on various health topics and informed that free health screenings are available. The health screenings include cholesterol level, blood pressure, body composition, and several other tests. As seniors entered the screening area at the St. George Civic Center, they had the option of completing a health survey. A convenience sample of 670 of 2,122 seniors completed the survey. These individuals were aged 50 years and older and were among the approximately 7,000 participants at the 2002 Games.

\section{Questionnaire}

The questionnaire consisted of 68 items involving demographics, lifestyle, and health history. It also included items related to perceived benefits associated with a healthy diet. Health history and lifestyle questions were taken from those found in the Behavioral Risk Factor Surveillance System (BRFSS) [9]. Potential benefits associated with a healthy diet were selected by the authors to repre- sent personal, social, and health aspects. Five researchers experienced in survey design assessed the quality of the questionnaire. An additional 10 experts in behavior change theory evaluated whether the instrument's content was appropriate for measuring health history, lifestyle, and reasons for adopting a healthy diet. Finally, 10 individuals aged 50 years and older assessed the questionnaire for readability and whether the questions made sense.

Demographic variables included age (50-59, 60-69, 7079 , and 80 years and older), gender, marital status (married or cohabitating, previously married, and never married), education (less than high school, high school degree, some college, bachelor degree, masters or doctoral degree), and annual household income $(<\$ 35,000$, $\$ 35,000-<\$ 50,000, \$ 50,000-<\$ 75,000$, and $\$ 75,000+)$. The fact that approximately $94 \%$ of the survey participants were white, non-Hispanic, led us to disregard race as a variable in the analysis.

Lifestyle variables were based on questions about smoking status ("Do you smoke: currently, previously but not within the last six months, never"); alcohol consumption ("Do you drink alcohol: currently, previously but not within the last six months, never"); and diet. The four questions related to diet were:

- "On average, how many days per week do you consume at least 5 servings of fruit and vegetables?"

- "The recommended daily intake for fiber is $20-35$ grams per day. On average, how many days per week do you consume at least the minimum amount? (Example: 2 grams = 1 slice of whole wheat bread, 1 medium apple, banana, or orange, $1 / 2$ cup carrots, corn, or green beans; 4 grams $=1$ / 2 cup berries, peas, broccoli, or spinach; 5 grams $=1 / 2$ cup all bran cereal, rice or pasta)."

• "Do you take a daily multivitamin supplement?"

• "Are you conscientious about your diet?"

Health history variables were determined from questions about previously diagnosed chronic disease (cancer, heart disease, diabetes, and lung disease); perceived weight ("Do you consider yourself to be: underweight, of normal weight, overweight, or obese?"); and current health status ("What would you say your current overall health status is: excellent, very good, good, fair, or poor?").

Finally, 8 Likert-scale questions (agree, neutral, disagree) evaluated personal reasons for adopting their current diet: to satisfy likes/dislikes, to feel a sense of control, to experience a higher level of spirituality, for social reasons, peer 
Table I: Frequency distributions of demographic, lifestyle, and health history characteristics for Senior Games participants

\begin{tabular}{|c|c|c|}
\hline & No. & $\%$ \\
\hline \multicolumn{3}{|l|}{ Age } \\
\hline $50-59$ & 167 & 24.9 \\
\hline $60-69$ & 349 & 52.1 \\
\hline $70-79$ & 133 & 19.9 \\
\hline $80+$ & 21 & 3.1 \\
\hline \multicolumn{3}{|l|}{ Gender } \\
\hline Male & 423 & 63.1 \\
\hline Female & 247 & 36.9 \\
\hline \multicolumn{3}{|l|}{ Marital Status } \\
\hline Married (including 7 cohabitating) & 553 & 82.9 \\
\hline Previously married & 99 & 14.8 \\
\hline Never married & 15 & 2.3 \\
\hline \multicolumn{3}{|l|}{ Education } \\
\hline Less than High School & 18 & 2.7 \\
\hline High School degree & 128 & 19.3 \\
\hline Some college & 203 & 30.7 \\
\hline Bachelor degree & 160 & 24.2 \\
\hline Masters and/or Doctoral degree & 153 & 23.1 \\
\hline \multicolumn{3}{|l|}{ Annual Household Income } \\
\hline$<\$ 35,000$ & 134 & 20.9 \\
\hline$\$ 35,000-<\$ 50,000$ & 149 & 23.3 \\
\hline$\$ 50,000-<\$ 75,000$ & 180 & 28.1 \\
\hline$\$ 75,000+$ & 177 & 27.7 \\
\hline \multicolumn{3}{|l|}{ Do you consider yourself to be religiously active? } \\
\hline Yes & 404 & 60.6 \\
\hline No & 263 & 39.4 \\
\hline \multicolumn{3}{|l|}{ Smoking Status } \\
\hline Current & 28 & 4.2 \\
\hline Previous, but not within the last six months & 195 & 29.4 \\
\hline Never & 441 & 66.4 \\
\hline \multicolumn{3}{|l|}{ Alcohol Drinking Status } \\
\hline Current & 351 & 53.7 \\
\hline Previous, but not within the last six months & 85 & 13.0 \\
\hline Never & 218 & 33.3 \\
\hline \multicolumn{3}{|l|}{ Perceived Weight } \\
\hline Underweight & 21 & 3.1 \\
\hline Normal weight & 388 & 57.9 \\
\hline Overweight & 254 & 37.9 \\
\hline Obese & 7 & 1.0 \\
\hline \multicolumn{3}{|l|}{ What is your current overall health status? } \\
\hline Excellent & 170 & 25.4 \\
\hline Very good & 310 & 46.3 \\
\hline Good & 173 & 25.8 \\
\hline Fair & 16 & 2.4 \\
\hline Poor & 1 & 0.1 \\
\hline \multicolumn{3}{|l|}{ History of the following chronic diseases: } \\
\hline Cancer & 125 of 668 & 18.7 \\
\hline Heart disease & 83 of 670 & 12.4 \\
\hline Diabetes & 43 of 670 & 6.4 \\
\hline Lung disease & 29 of 670 & 4.3 \\
\hline
\end{tabular}

acceptance, to prevent disease, to prolong life, and to improve quality of life.
Statistical analysis

Frequency distributions are presented, along with results from bivariate analysis, analysis of variance, and multiple logistic regression analysis. Statistical significance was 
Table 2: Frequency distributions of dietary behavior for the Senior Games participants

\begin{tabular}{|c|c|c|}
\hline & No. & $\%$ \\
\hline \multicolumn{3}{|c|}{$\begin{array}{l}\text { On average, how many days per week do you consume } \\
\text { at least } 5 \text { servings of fruit and vegetables? }\end{array}$} \\
\hline 0 & 54 & 8.2 \\
\hline 1 & 66 & 9.9 \\
\hline 2 & 77 & 11.6 \\
\hline 3 & 95 & 14.3 \\
\hline 4 & 96 & 14.5 \\
\hline 5 & 89 & 13.4 \\
\hline 6 & 62 & 9.4 \\
\hline 7 & 124 & 18.7 \\
\hline \multicolumn{3}{|c|}{$\begin{array}{l}\text { The recommended daily intake for fiber is } 20-35 \text { grams per day. } \\
\text { On average, how many days per week do you consume at least the minimum amount? } \\
\text { (Example: } 2 \text { grams }=\text { I slice of whole wheat bread, I medium apple, banana, or orange, } \\
1 / 2 \text { cup carrots, corn, or green beans; } 4 \text { grams }=1 / 2 \text { cup berries, peas, broccoli, or spinach; } \\
5 \text { grams }=1 / 2 \text { cup all bran cereal, rice or pasta). }\end{array}$} \\
\hline 0 & 28 & 4.3 \\
\hline 1 & 29 & 4.4 \\
\hline 2 & 31 & 4.7 \\
\hline 3 & 58 & 8.8 \\
\hline 4 & 60 & 9.2 \\
\hline 5 & 102 & 15.6 \\
\hline 6 & 79 & 12.1 \\
\hline 7 & 268 & 40.9 \\
\hline \multicolumn{3}{|c|}{ Do you take a daily multivitamin supplement? } \\
\hline Yes & 462 & 70.1 \\
\hline No & 197 & 29.9 \\
\hline \multicolumn{3}{|c|}{ Are you conscientious about your diet? } \\
\hline Yes & 514 & 77.5 \\
\hline No & 149 & 22.5 \\
\hline
\end{tabular}

based on the Chi-square test in the bivariate analysis and the F-statistic under Type I Sums of Squares in the analysis of variance models. Maximum likelihood estimates were evaluated for statistical significance in the logistic regression analysis using the Wald Chi-square statistic. All data were analyzed using the Statistical Analysis System (SAS) software for personal computers, release 9.0. Unless indicated otherwise, tests of significance were two-tailed, based on the 0.05 level.

\section{Results}

Frequency distributions of the study participants according to selected demographic, lifestyle, and health history variables are presented in Table 1 . The most frequent representation within each variable was being 60-69 years of age, male, married, having some college, having an annual household income of $\$ 50,000$ or more, never having smoked, being a current alcohol drinker, of perceived normal weight, and of very good overall health status. Of the chronic conditions considered, cancer was most common and lung disease least common.
Frequency distributions for the four dietary behavior variables are presented in Table 2. Daily fiber intake was more common than daily consumption of five fruit and vegetable servings per day. Approximately $70 \%$ took a daily multivitamin supplement and over $77 \%$ indicated they were conscientious about their diet.

The mean number of days per week that participants consumed five or more fruit and vegetables and ate at least the minimum amount of fiber is presented according to the demographic, lifestyle, and health history variables in Table 3. The mean number of days per week of fruit and vegetable consumption significantly varied by age, gender, weight, and health status. The most frequent daily fruit and vegetable consumption was among seniors 70 to 79 years of age, males, those not overweight or obese, and those of excellent health. The mean number of days per week of minimum fiber intake significantly varied across smoking status, alcohol drinking, weight, and health status. Daily fiber intake was most frequent among seniors who did not currently smoke, who currently or previously consumed alcohol, who were not overweight or obese, and who were in excellent health. 
Table 3: Mean number of days per week, on average, that participants consumed five or more fruit and vegetables and consumed at least the minimum amount of fiber according to selected demographic, lifestyle, and health history variables

\begin{tabular}{|c|c|c|}
\hline & Fruit and Vegetables & Fiber \\
\hline \multicolumn{3}{|l|}{ Age } \\
\hline $50-59$ & 3.6 & 4.9 \\
\hline $60-69$ & 3.8 & 5.1 \\
\hline 70-79 & 4.4 & 5.5 \\
\hline $80+$ & 4.0 & 5.4 \\
\hline \multicolumn{3}{|l|}{ Gender } \\
\hline Male & 3.7 & 5.1 \\
\hline Female & 4.2 & 5.2 \\
\hline \multicolumn{3}{|l|}{ Marital Status } \\
\hline Married (including 7 cohabitating) & 3.9 & 5.1 \\
\hline Previously married & 3.7 & 5.2 \\
\hline Never married & 4.5 & 6.1 \\
\hline \multicolumn{3}{|l|}{ Education } \\
\hline Less than High School & 3.3 & 5.3 \\
\hline High School & 3.7 & 5.1 \\
\hline Some college & 3.9 & 4.8 \\
\hline Bachelor degree & 3.9 & 5.5 \\
\hline Master or Doctorate degree & 4.0 & 5.2 \\
\hline \multicolumn{3}{|l|}{ Annual Household Income } \\
\hline$<\$ 35,000$ & 3.7 & 5.0 \\
\hline$\$ 35,000-<\$ 50,000$ & 3.9 & 5.1 \\
\hline$\$ 50,000-<\$ 75,000$ & 3.7 & 4.9 \\
\hline$\$ 75,000$ & 4.1 & 5.3 \\
\hline \multicolumn{3}{|l|}{ Do you consider yourself to be religiously active? } \\
\hline Yes & 3.9 & 5.1 \\
\hline No & 3.8 & 5.2 \\
\hline \multicolumn{3}{|l|}{ Smoking Status } \\
\hline Current & 3.2 & 3.7 \\
\hline Previous, but not within the last six months & 3.9 & 5.2 \\
\hline Never & 3.9 & 5.2 \\
\hline \multicolumn{3}{|l|}{ Alcohol Drinking Status } \\
\hline Current & 3.9 & 5.3 \\
\hline Previous, but not within the last six months & 4.0 & 5.4 \\
\hline Never & 3.7 & 4.8 \\
\hline \multicolumn{3}{|l|}{ Perceived Weight } \\
\hline Underweight & 4.3 & 5.3 \\
\hline Normal weight & 4.2 & 5.3 \\
\hline Overweight/Obese & 3.4 & 4.8 \\
\hline \multicolumn{3}{|l|}{ What is your current overall health status? } \\
\hline Excellent & 4.4 & 5.4 \\
\hline Very good & 3.8 & 5.2 \\
\hline Good & 3.5 & 4.9 \\
\hline Fair/Poor & 3.2 & 3.9 \\
\hline \multicolumn{3}{|l|}{ History of Chronic Disease* } \\
\hline Yes & 3.9 & 5.0 \\
\hline No & 3.8 & 5.2 \\
\hline
\end{tabular}

Significant F-statistics and corresponding $P$ values in the Fruit and Vegetables column were: $F(3)=3.7,0.0123$ for age; $F(I)=6.0,0.0147$ for gender; $F(2)=8.6,0.0002$ for weight; and $F(3)=5.3,0.0013$ for health status. For the Fiber column these were: $F(2)=6.47,0.0017$ for smoking status; $F(2)$ $=4.14,0.0163$ for alcohol drinking; $F(2)=4.4,0.0127$ for weight; and $F(3)=3.4,0.0170$ for health status. *Chronic disease included cancer, heart disease, diabetes, and lung disease.

Of the demographic, lifestyle, and health history variables presented in the table, only age (Chi-square $(3)=22.1$, p $<0.0001$ ) and gender (Chi-square $(1)=6.0, \mathrm{p}=0.0140$ ) were associated with taking a daily multivitamin supple- ment. The percentage taking a daily multivitamin supplement tended to increase with age: $58.8 \%$ in ages $50-59$, $70.3 \%$ in ages $60-69,84.0 \%$ in ages $70-79$, and $70.0 \%$ in ages 80 years and older. In addition, $66.8 \%$ of men com- 
Table 4: Level of agreement with perceived benefits associated with a healthy diet among individuals who indicated they were conscientious about their diet

\begin{tabular}{lccc}
\hline & Agree & Neutral & Disagree \\
\hline To improve quality of life & 95.0 & 4.4 & 0.6 \\
To increase longevity & 88.9 & 9.1 & 2.0 \\
To prevent disease & 84.5 & 12.1 & 3.4 \\
To feel a sense of control & 66.5 & 28.2 & 8.3 \\
To satisfy likes or dislikes & 64.4 & 26.4 & 9.2 \\
To experience a higher level of & 32.8 & 41.2 & 25.9 \\
spirituality & 32.2 & 43.8 & 24.0 \\
For social reasons & 11.6 & 34.9 & 53.6 \\
Peer acceptance & & & \\
\hline
\end{tabular}

Table 5: The association between the odds of agreeing with personal reasons for being conscientious about one's diet and gender, education, and religion*

\begin{tabular}{lcc}
\hline Personal Reasons for Being Conscientious about Diet & GEN & EDU \\
\hline $\begin{array}{l}\text { To improve quality of life } \\
\text { To increase longevity }\end{array}$ & & NS/NS/+ \\
To prevent disease & & \\
$\begin{array}{l}\text { To feel a sense of control } \\
\text { To satisfy likes or dislikes }\end{array}$ & & NS/-/- \\
To experience a higher level of spirituality & + & NS/NS/- \\
For social reasons & + & + \\
Peer acceptance & &
\end{tabular}

* Variables were simultaneously estimated, based on the variables listed at the top of the table, using multiple logistic regression. GEN: gender (male vs. female); EDU: education (less than high school or high school degree vs. graduate degree / some college or technical school vs. graduate degree / bachelors degree vs. graduate degree); REL: consider yourself religiously active (yes vs. no); NS: not statistically significant at the 0.05 level.

pared with $75.8 \%$ of women took a daily multivitamin supplement. The variables related to being conscientious about one's diet were gender (Chi-square $(1)=8.2, \mathrm{p}=$ 0.0042 ), weight (Chi-square $(2)=14.7, \mathrm{p}=0.0006)$, and health status (chi-square $(3)=24.2, \mathrm{p}<0.0001)$. Males were less likely than females to indicate that they were conscientious about their diet (74.0\% vs. $83.6 \%)$; increasing weight was inversely related to being conscientious about one's diet $(90.5 \%$ of those underweight, $81.9 \%$ of those of normal weight, and $69.9 \%$ of those overweight/ obese); and health status was associated with being conscientious about one's diet $(86.4 \%$ of excellent health, $79.8 \%$ of very good health, $64.9 \%$ of good health, and $75 \%$ of fair/poor health).

The 514 seniors who indicated that they were conscientious about their diet attributed their dietary behavior most frequently to perceived health benefits, followed by perceived personal benefits and social benefits (Table 4).

Agreement (vs. otherwise) with each of the perceived benefits associated with a healthy diet were treated as response variables in multiple logistic regression models (Table 5). These models initially included the demographic, lifestyle, and disease history variables in Table 1. However, after applying backward stepwise regression, where variables were sequentially deleted if they failed to be significant at the 0.1 level, only gender, education, or religiosity remained significant in at least one of the eight models. In turn, each of the eight dependent variables was regressed on these three variables. Statistically significant variables in each of the models are represented where symbols $(+/-)$ occur, with the symbol representing the direction of association. Those with more education were more likely to agree with preventing disease as a motivation for being conscientious about their diet. In contrast, the more highly educated were less likely to agree that they were motivated by a desire to experience a higher level of spirituality or a desire for peer acceptance. Males were more likely than females to agree that perceived social benefits or a desire for peer acceptance motivated their being conscientious about dietary behavior. Finally, agreement that a higher level of spirituality motivated 
their being conscientious about their diet was higher among religiously active individuals.

\section{Discussion}

A national study has shown that a large proportion of seniors in the U.S. do not adhere to diets that meet the recommendations for vitamins and minerals [10]. Thus interventions focusing on this growing subgroup of the population seem warranted. An understanding of which seniors are most likely to adopt a proper diet, the relative importance they place on certain perceived benefits for motivating a healthy diet, and whether these perceived benefits are associated with other demographic, lifestyle, and health history variables is needed for developing effective health programs.

Women were more likely than men to report being conscientious about their diet. This is consistent with a number of studies addressing women's attitudes about diet. In a Norwegian study, women, more than men, reported changing their diet to align with their country's dietary recommendations and were more likely to seek out health information [11]. In a cohort study evaluating demographic factors as predictors of self-initiated dietary change, women and more highly educated individuals changed their diets to consume significantly less fat and more fruit and vegetables [12]. In a study of adults going to a family practice clinic, women were five times more likely to be dissatisfied with their weight and body image than men and were twice as likely as men to feel guilty when eating [13]. In addition, studies have identified a greater social anxiety about eating and more dissatisfaction with body shape and image in women than in men $[14,15]$. These factors may help explain why females were more likely to report being conscientious about their diet.

Weight and health status were also related to being conscientious about one's diet. This is not surprising, given that healthy eating is associated with lower body weight and better health [1]. There is also evidence that weight status can be a motivating factor for initiating healthy eating behavior. In one study involving adults enrolled in a community weight gain prevention program, BMI was positively associated with dieting behavior [16]. Health behaviors tend to cluster together. For example, individuals with a healthy diet are more likely to be non-smokers and to be physically active [17-19]. There are several potential explanations for this association. First, as one healthy behavior is adopted and successfully implemented, self-efficacy improves and other healthy practices are more likely to be attempted. Second, individuals already practicing one healthy behavior find it easier to begin other healthy behaviors (e.g., physical activity may be easier for nonsmokers than for smokers). Finally, a greater desire to be healthy in some individuals may moti- vate them to put forth more effort to initiate and maintain a wide range of healthy behaviors.

Consistent with previously published associations [20], multivitamin use was positively associated with age and was more prevalent among women in our study. Use of dietary supplements, including multivitamins, appears to be associated primarily with attitudes about possible health benefits and the influence of the media. In a study evaluating dietary supplement use in British women, supplement users were more likely than non-users to believe that taking a supplement would prevent illness and promote health [21]. A similar study reported that supplement users, as well as non-users, perceived the media to be a powerful influence on supplement use [22]. Differences in attitudes and knowledge toward health and the benefits of multivitamin use may explain why women and older individuals were more likely to take a multivitamin.

The data show that items related to health such as improved quality of life, increased longevity, and disease prevention were the strongest motivating factors for consuming a healthy diet. Participants also agreed that spiritual and social benefits are important, but to a much lesser extent. The higher level of agreement with health-related items is consistent with the findings of Satia et al., where study participants placed the highest value on feeling better and controlling an existing medical problem [3].

Education was positively associated with participants' agreement that they were conscientious about their diet to prevent disease. In a study based on data from the NHANES III and the Quebec Nutrition Survey, higher levels of education were associated with better compliance with national nutritional recommendations for nutrients [23]. A cross-sectional study of British adults found that nutrition knowledge declined with lower educational attainment [24]. A study of American young adults found that non-students were less likely to comply with the Dietary Guidelines than their college-student peers [25]. Higher levels of education could provide knowledge and cognitive assets that are disease preventive. More knowledge of disease processes, diet, or other knowledge not directly related to health may explain why those with more education were more likely to agree that they were conscientious about their diet to prevent disease.

Many study participants agreed that they were conscientious about their diet to feel a sense of control. Resisting hunger is a triumph over will, and exercising control over eating may be a convenient way to promote self-control in general [26]. Fairburn et al. hypothesized that anorexia nervosa results from an extreme, disordered need for self- 
control [27]. This study suggests that many individuals with normal eating patterns are also motivated to initiate healthy eating behaviors in order to attain self-control and self-actualization. For those desiring self-control, positive experiences with exerting power over self may also be a factor in maintaining healthy eating behavior.

The majority of study participants agreed that they were conscientious about their diet to satisfy likes or dislikes. This is consistent with studies that have emphasized the importance of taste and food preferences in food choice $[7,8]$. Eertmans et al. hypothesized that food likes and dislikes are central to the development and maintenance of eating behaviors [8]. Another study with rats showed that improving the flavor of food can significantly increase energy consumption when nutrient composition is held constant [28]. In other words, taste is a powerful motivator - perhaps more powerful than energy density - in deciding what foods to consume and in what quantity.

Some participants indicated that experiencing a higher level of spirituality was a motivator for being conscientious about their diet. This may be related to ethical concerns about food, such as using animal products [29] and consuming genetically altered foods [30], where being conscientious about their diet would include avoidance of foods with associated moral issues as determined by individual perceptions of acceptability. Individuals reporting being religiously active were more likely to agree that they were conscientious about their diet in order to experience a higher level of spirituality. This is not unexpected, because those who are religiously active may be more willing to exert themselves for religion (i.e. attend church services, read sacred texts, make effort to follow church doctrines and commandments) than those not religiously active, and being conscientious about their diet could be considered part of religious practice. For example, according to the laws of kashrut, the body of Jewish law dealing with what foods can and cannot be eaten and how those foods must be prepared and eaten, certain animals may not be eaten, and animals that may be eaten must be killed in accordance with Jewish law [31]. Studies have identified religions with strong health directives such as in Latter-day Saints (also called Mormons) and Seventh-day Adventists, which strongly discourage tobacco use and alcohol drinking, and, in the case of the Seventh-day Adventists, encourage dietary habits that are vegetarian $[32,33]$.

Among those conscientious about their diet, individuals with higher levels of education were less likely to agree that they were conscientious about their diet to achieve a higher level of spirituality. This is consistent with the potential secularizing influence of education. Scientific thinking encouraged by education may be perceived as counter to religious views and behaviors that are perhaps based on prescientific and irrational thinking [34,35].

It may be that older Americans in our study agreed that they were conscientious about their diet for social reasons because of pleasure derived from eating with others. A recent study involving older women identified one social benefit of eating: the pleasure of eating together. The study showed that women living alone tended to simplify cooking and eating, while those with company perceived meals as a pleasure [36]. Two studies, one involving college students and one observing adult behavior, found that food intake increases dramatically when meals are eaten with others versus eating alone $[37,38]$. The culture and religion of the family, as well as the perceived social acceptability or "coolness" of food were identified as factors in the food choices of adolescents [39]. Pleasure from eating with others, social acceptability of food, and cultural preferences all influence dietary behavior and may be social motivations for consuming a healthy diet.

It is unclear why men were more likely to agree that they were conscientious about their diet for social reasons. It may be that men may be more likely to recognize the benefits of eating in groups and are more likely to rely on others for cooking and meal preparation.

Another social reason for being conscientious about diet could be to control weight and improve body image. A desire to control weight and be physically attractive has been shown to motivate older adults to diet $[40,41]$. Social influences have been cited as the strongest force in initiation of dieting [42]. Dissatisfaction with body image also strongly motivates dietary change [3]. The pressure from others to change diet, as well as differences in interpersonal characteristics, could explain why some individuals are conscientious about their diets for social reasons.

Those who indicated that they were conscientious about their diet for peer acceptance were probably influenced by social desirability. Cultural perceptions of which foods are "good" and "bad" have been shown to influence food choices [43]. The desire to appear to be consuming "healthy" foods or simply to "fit in, " could motivate older Americans to be conscientious about their diet. The utility of group support in initiating and maintaining diet behavior is well documented, with dietary interventions generally being more successful when social support is included. As one example, in a study of dietary modification in renal disease patients, social support was significantly related to dietary adherence [44]. The importance of feeling a sense of oneness and camaraderie cannot be overlooked as a motivating factor in consuming a healthy diet. 
There are some limitations to this study. First, since $94 \%$ of study subjects were white, non-Hispanic, the results can not be generalized to minority groups. Second, about $72 \%$ of study participants reported being in excellent or very good health, and their motivation to consume a healthy diet could be different from those with poorer health status. Better overall health status was associated with higher consumption of fruit, vegetables, and fiber but was not associated with the level of agreement with items associated with being conscientious about one's diet. Third, since the data are based on a self-report questionnaire, a potential for social acceptability bias exists. However, individuals assisting the participants taking the questionnaire were instructed to ask the participants to be as honest as possible with their responses. They also emphasized the anonymous nature of the survey. Only a very small percentage of those participating in the study failed to answer all the questions, hence response bias to any of the given questions is not a concern.

\section{Conclusions}

Food choice in the elderly is influenced by a complex combination of factors including, but not limited to, a desire to prevent disease, improve the quality of life, and increase longevity; social reasons; taste and sensory considerations; a desire to feel a sense of control; and a desire for peer acceptance. This indicates that health programs aimed towards improving the diet of older Americans must take a multifactorial approach and consider the potential health, interpersonal, and social benefits of consuming a healthy diet.

As health considerations were the strongest motivating factor in being conscientious about diet, programs should emphasize the potential of a good diet to improve the quality of life, prevent disease, and increase longevity. Social desirability and pleasure derived from eating also appear to motivate healthy eating and should be considered in implementing health programs.

In general, seniors reporting being in good health, of normal weight, and not smoking were most likely to consume adequate amounts of fruit and vegetables, fiber, and be conscientious about their diets. This implies that extra attention and effort is needed to encourage those who are overweight/obese and in poor health to adopt healthy eating behaviors.

\section{Competing interests \\ None declared.}

\section{Authors' contributions}

RMM conceived of the study, participated in the design of the study, performed the statistical analysis, and drafted the manuscript. ECS participated in the literature review and writing of the manuscript. All authors read and approved the final manuscript.

\section{Acknowledgments}

We wish to thank Steven W. Heiner for making it possible for us to survey the 2002 World Senior Games participants. We also wish to thank Alison Wood and other students from Brigham Young University who volunteered their time to administer the survey.

\section{References}

I. U.S. Department of Health and Human Services: Healthy People 2010 . With Understanding and Improving Health and Objectives for Improving Health. Volume 2. 2nd edition. Washington, DC: U.S. Government Printing Office; 2000.

2. U.S. Department of Agriculture: Nutrition and Your Health: Dietary Guidelines for Americans. Washington, D.C.: U.S. Govt. Print. Off., Home and Garden Bulletin 52000, 232:

3. Satia JA, Kristal AR, Curry S, Trudeau E: Motivations for healthful dietary change. Public Health Nutr 200I, 4:953-959.

4. Turrell G, Hewitt B, Patterson C, Oldenburg B, Gould T: Socioeconomic differences in food purchasing behavior and suggested implications for diet-related health promotion. J Hum Nutr Diet 2002, I 5:355-364.

5. Mela DJ: Food choice and intake: the human factor. Proc Nutr Soc 1999, 58:513-521.

6. Steptoe A, Pollard TM, Wardle J: Development of a measure of the motives underlying the selection of food: the food choice questionnaire. Appetite 1995, 25:267-284.

7. Drewnowski A: Taste preferences and food intake. Annu Rev Nutr 1997, I 7:237-253.

8. Eertmans A, Baeyens F, Van den Bergh O: Food likes and their relative importance in human eating behavior: review and preliminary suggestions for health promotion. Health Educ Res 2001, 1 6:443-456.

9. Centers for Disease Control and Prevention (CDC): Behavioral Risk Factor Surveillance System Survey Questionnaire. Atlanta, Georgia: U.S. Department of Health and Human Services, Centers for Disease Control and Prevention 2001.

10. Ryan AS, Craig LD, Finn SC: Nutrient intakes and dietary patterns of older Americans: a national study. J Gerontol 1992, 47:MI45-MI50.

II. Fagerli RA, Wandel M: Gender differences in opinions and practices with regard to a "healthy diet". Appetite 1999, 32:171-190.

12. Kristal AR, Hedderson MM, Patterson RE, Neuhouser M, Neuhauser $\mathrm{ML}$ : Predictors of self-initiated, healthful dietary change. J Am Diet Assoc 200I, I 01 : 762-766.

13. Seim HC, Fiola JA: A comparison of attitudes and behaviors of men and women toward food and dieting. Fam Pract Res J 1990, 10:57-63.

14. Rolls BJ, Fedoroff IC, Guthrie JF: Gender differences in eating behavior and body weight regulation. Health Psychol 1991, I0:133-142.

15. Furnham A, Badmin N, Sneade I: Body image dissatisfaction: gender differences in eating attitudes, self-esteem, and reasons for exercise. J Psychol 2002, I 36:58I-596.

16. Neumark-Sztainer D, Sherwood NE, French SA, Jeffery RW: Weight control behaviors among adult men and women: cause for concern? Obes Res 1999, 7:179-188.

17. Emmons KM, Marcus BH, Linnan L, Rossi JS, Abrams DB: Mechanisms in multiple risk factor interventions: smoking, physical activity, and dietary fat intake among manufacturing workers: Working Well Research Group. Prev Med 1994, 23:48I-489.

I8. Ma J, Betts NM, Hampl JS: Clustering of lifestyle behaviors: the relationship between cigarette smoking, alcohol consumption, and dietary intake. Am J Health Promot 2000, I 5: I07-I I7.

19. Thompson DH, Warburton DM: Lifestyle differences between smokers, ex-smokers and nonsmokers, and implications for their health. Psychol Health 1992, 7:31I-32I.

20. Balluz LS, Kieszak SM, Philen RM, Mulinare J: Vitamin and mineral supplement use in the United States. Results from the third National Health and Nutrition Examination Survey. Arch Fam Med 2000, 9:258-262. 
21. Conner M, Kirk SF, Cade JE, Barrett JH: Why do women use dietary supplements? The use of the theory of planned behaviour to explore beliefs about their use. Soc Sci Med 200I, 52:62I-633.

22. Conner M, Kirk SF, Cade JE, Barrett JH: Environmental influences: factors influencing a woman's decision to use dietary supplements. J Nutr 2003, 1 33: I 978S-1982S.

23. Dubois L, Girard M: Social position and nutrition: a gradient relationship in Canada and the USA. Eur J Clin Nutr 200I, 55:366-373.

24. Parmenter K, Waller J, Wardle J: Demographic variation in nutrition knowledge in England. Health Educ Res 2000, 15:163-174.

25. Georgiou CC, Betts NM, Hoerr SL, Keim K, Peters PK, Stewart B, Voichick J: Among young adults, college students and graduates practiced more healthful habits and made more healthful food choices than did nonstudents. J Am Diet Assoc 1997, 97:754-759.

26. Smith JL: The psychology of food and eating New York: Palgrave; 2002:89-94.

27. Fairburn CG, Shafran R, Cooper Z: A cognitive behavioural theory of anorexia nervosa. Behav Res Ther 1999, 37:I-I3.

28. Sclafani A: Psychobiology of food preferences. Int J Obes Relat Metab Disord 200I, 25:Suppl 5:SI3-16.

29. Pollard TM, Steptoe A, Wardle J: Motives underlying healthy eating: using the Food Choice Questionnaire to explain variation in dietary intake. J Biosoc Sci 1998, 30:165-179.

30. Shepherd R: Social determinants of food choice. Proc Nutr Soc | 999, 58:807-8|2.

31. Judaism I0I: Kashrut: Jewish Dietary Laws [http://www.jew faq.org/kashrut.htm]

32. West DW, Lyon JL, Gardner JW: Cancer risk factors: an analysis of Utah Mormons and non-Mormons. J Natl Cancer Inst 1980, 65:1083-1095.

33. Fraser GE: Associations between diet and cancer, ischemic heart disease, and all-cause mortality in non-Hispanic white California Seventh-day Adventists. Am J Clin Nutr 1999, 70(3 Suppl):532S-538S.

34. Madsen GE, Vernon GM: Maintaining the faith during college: $\mathbf{A}$ study of campus religious group participation. Rev Relig Res 1983, 25:|27-4|.

35. Funk RB, Willits FK: College attendance and attitude change: $\mathbf{A}$ panel study 1970-8I. Sociol Educ 1987, 60:224-3I.

36. Gustafsson K, Sidenvall B: Food-related health perceptions and food habits among older women. J Adv Nurs 2002, 39:164-173.

37. Redd $M$, de Castro JM: Social facilitation of eating: effects of social instruction on food intake. Physiol Behav 1992, 52:749-754.

38. de Castro JM, Brewer EM: The amount eaten in meals by humans is a power function of the number of people present. Physiol Behav 1992, 5 I: I2I-125.

39. Neumark-Sztainer D, Story M, Perry C, Casey MA: Factors influencing food choices of adolescents: findings from focusgroup discussions with adolescents. J Am Diet Assoc 1999, 99:929-937.

40. Allaz AF, Bernstein M, Rouget P, Archinard M, Morabia A: Body weight preoccupation in middle-age and ageing women: $A$ general population survey. Int J Eat Disord 1998, 23:287-294.

41. Franzoi SL, Koehler V: Age and gender differences in body attitudes: a comparison of young and elderly adults. Int $\int$ Aging Hum Dev 1998, 47: I-I0.

42. Huon GF, Strong KG: The initiation and the maintenance of dieting: structural models for large-scale longitudinal investigations. Int ] Eat Disord 1998, 23:36 I-369.

43. Furst T, Connors M, Bisogni CA, Sobal J, Falk LW: Food choice: $\mathbf{A}$ conceptual model of the process. Appetite 1996, 26:247-265.

44. Milas NC, Nowalk MP, Akpele L, Castaldo L, Coyne T, Doroshenko L, Kigawa L, Korzec-Ramirez D, Scherch LK, Snetselaar L: Factors associated with adherence to the dietary protein intervention in the Modification of Diet in Renal Disease Study. J Am Diet Assoc 1995, 95: 1295-1300.
Publish with Biomed Central and every scientist can read your work free of charge

"BioMed Central will be the most significant development for disseminating the results of biomedical research in our lifetime. "

Sir Paul Nurse, Cancer Research UK

Your research papers will be:

- available free of charge to the entire biomedical community

- peer reviewed and published immediately upon acceptance

- cited in PubMed and archived on PubMed Central

- yours - you keep the copyright

Submit your manuscript here:

http://www.biomedcentral.com/info/publishing_adv.asp
BiolMedcentral 